\title{
Relationship of Tomato Fruit Sugar Concentration with Physical and Chemical Traits and Linkage of RAPD Markers
}

\author{
N. Georgelis and J.W. Scott \\ Gulf Coast Research and Education Center, University of Florida, 5007 60th Street East, Bradenton, \\ FL 34203-9324 \\ E.A. Baldwin \\ U.S. Department of Agriculture, Agricultural Research Service, Citrus and Subtropical Products \\ Laboratory, 600 Avenue S N.W., Winter Haven, FL 33881
}

\begin{abstract}
ADDITIONAL INDEX WORDS. Lycopersicon esculentum var. cerasiforme, RAPD, glucose, fructose, HPLC, fruit size, plant habit, soluble solids, earliness, pedicel

ABSTRACT. Small-fruited cherry tomato accession PI 270248 (Lycopersicon esculentum Mill. var. cerasiforme Dunal) with high fruit sugars was crossed to large-fruited inbred line Fla.7833-1-1-1 (7833) that had normal (low) fruit sugar. Sugars in the $\mathrm{F}_{2}$ were positively correlated with soluble solids, glucose, fructose, $\mathrm{pH}$, and titratable acidity, and inversely correlated with fruit size. Earliness was not significantly correlated with sugars but was negatively correlated with fruit size. Thus, the lack of a sugar-earliness correlation indirectly indicates a trend for early tomato plants to be lower in sugars than later maturing plants. Sugars were not correlated with yield or pedicel type. Fruit from indeterminate plants had significantly more sugars than from determinate plants. Six random amplified polymorphic DNA (RAPD) markers linked to high sugars were found, five dominant (OPAE 4, UBC 731, UBC 744, UBC 489, UBC 290) and one co-dominant (UBC 269). Five of the markers were also linked to small fruit size and one of these also was linked to low yield (UBC 290). The sixth marker (UBC 269) was linked to indeterminate plant habit. UBC 731, UBC 489, and possibly OPAE 4 were in one linkage group, while UBC 744 and UBC 290 were in another linkage group. Combinations of all the markers together explained $35 \%$ of the sugar variation in the $F_{2}$ grown in Spring 2002.
\end{abstract}

Consumers often are dissatisfied with the flavor of fresh-market tomatoes (Lycopersiconesculentum) (Bruhn etal.,1991). In tomato breeding, there are priorities other than flavor that are important, such as high yield, disease resistance, and shipping ability, and it is difficult to breed for improved flavor (Scott, 2002). Indeed, flavor is a complicated trait influenced, mainly, by taste (sweetness, sourness) and aroma. Taste is basically determined by sugars and acids (Kader et al., 1977; Malundo et al., 1995; Stevens et al., 1977a, 1977b). Sugars in L. esculentum are mostly comprised of glucose and fructose with trace amounts of sucrose (Davies and Hobson, 1981; Stevens, 1972), and Petro-Turza (1987) attributed the sweet taste of tomato to reducing sugars. Fructose and glucose are found in almost equal quantities in tomato fruit with fructose being a little higher, while sucrose usually does not exceed 0.1\% (Davies and Hobson, 1981; Davies and Kempton, 1975; Petro-Turza, 1987). Citric and malic acids are the primary acids in tomato fruit with citric predominating and determining sourness (Davies and Hobson, 1981). Another important flavor component is aroma, which is determined by volatiles (Baldwin et al., 1998, 2000; Kazeniac and Hall, 1970; Krumbein and Auerswald, 1998). In tomato, more than 400 volatiles have been reported, but less than 30 are above the odor threshold (Tandon et al., 2000).

Part of the problem of poor flavor is that most commercial cultivars of fresh-market tomatoes have a low level of sugars [total soluble solids (SS) from 4\% to 5\%] (Kavanagh and McGlasson, 1983; McGlasson et al., 1983), including two most prominent

Received for publication 17 Oct. 2003. Accepted for publication 22 Mar. 2004. Florida Agricultural Experiment Station Journal Series No. R-09799. Thank you to Dr. Harry Klee for providing helpful advice. cultivars in Florida, 'Florida 47' and 'Sanibel' (SS = 4\% to 5\%) (N. Georgelis, unpublished data). Malundoet al.(1995) found that an increase of sugar level (glucose and fructose) higher than most large-fruited commercial cultivars enhanced the aroma intensity and made the overall flavor more acceptable within a certain acid concentration range. Additionally, Baldwin et al. (1998) showed that sugars were positively correlated with overall flavor acceptability. Hence, if the sugar level of the existing large-fruited fresh market cultivars was increased, it is likely that the overall flavor would be improved.

There are some accessions from wild tomato species with high fruit sugar levels, like L. chmielewskii Rick et al., L. hirsutum Humb. \& Bonpl., and L. pimpinellifolium Mill., which could be used as potential sources of sugars. However, some of them have sucrose as the predominant sugar with just small amounts of glucose and fructose. So, a possible transfer of genes from these species would probably change the type of sweetness in large-fruited tomatoes that usually have fructose and glucose as predominant sugars. Additionally, interspecific crosses usually entail a host of prebreeding tasks (Jones and Qualset, 1984).

Apart from the high sucrose level, L. hirsutum has been used as a source of the gene $F g r$, which modulates the ratio of fructose to glucose (Levin et al., 2000). More specifically, L. hirsutum has a fructose:glucose ratio of more than $1.5: 1$, which contrasts with L. esculentum where glucose and fructose are almost equimolar. This increased ratio can be transferred to L. esculentum without changing the overall sugar level, which means that the amount of fructose is increased and that of glucose is equally reduced. Biester (1925) showed that fructose is almost twice as sweet as glucose, which means that tomatoes with the Fgr gene should taste sweeter compared to tomatoes with an equal sugar level. 
However, the effect of that gene on the overall flavor remains unknown.

Other sources of high sugars are cherry tomatoes with elevated sugar levels. Their high sugar level is primarily determined by glucose and fructose and a transfer of these to large-fruited tomatoes would not be expected to change the type of sweetness perceived by consumers. In this study, the small cherry accession PI 270248 was studied as a potential source of high sugars. Apart from the sweet taste, its fruit were resistant to bacterial spot incited by Xanthomonas campestris pv. vesicatoria (Doidge) Dye (Scott et al., 1989).

A potential problem in the transfer of high sugars from all the above sources to large-fruited tomatoes is the transfer of undesirable traits such as low yield and small fruit size along with high sugar. Another problem is that sugar level is under polygenic control (Causse et al., 2001; Fulton et al., 2002), and is influenced by the environment (Saliba-Colombani et al., 2001). Backcrossing these genes into large-fruited tomatoes that have low sugar content would be difficult, as many generations would be required and errors would be encountered in phenotypic selection. Marker-assisted selection (MAS) could improve backcrossing efficiency. One objective of this research was to evaluate the relationship of high sugars derived from PI 270248 with other traits, such as yield, fruit size, and plant habit, to discern which ones may be important to consider in the transfer of high sugars into large-fruited tomato lines. Another goal was to find molecular markers linked to high sugars derived from PI 270248 that would facilitate selection in breeding programs.

There have been several cases where molecular markers (almost entirely RFLPs) linked to sugars were found. However, most of these studies used a wild species in the initial cross (Bernacchi et al., 1998; Tanksley et al., 1996). These markers may be useful in an attempt to transfer sugar from a wild species to large-fruited tomatoes, but they are not useful when the high sugar plant is the same species. Many of these markers do not show even a single polymorphism in an intraspecific cross (Foolad et al., 1993). Therefore, it was decided to try to find other markers linked to high sugars from PI 270248.

In this research, RAPD markers were chosen because they are inexpensive and give rapid results. RAPDs linked to high sugars would be very convenient to use in an attempt to select for high sugar phenotypes, especially when hundreds of individuals would have to be screened. One major problem with RAPDs linked to high sugars could be that some polymorphisms might also be linked to genes controlling undesirable traits. This could be due to tight linkage of genes controlling these traits with genes controlling sugar level, or due to pleiotropic effects. These kinds of polymorphisms may cause problems if MAS is used to incorporate high sugars from PI 270248 into large-fruited tomatoes. Traits such as plant habit, pedicel type, yield, earliness, and fruit size were measured along with sugars in this research. Thus, polymorphisms linked to high sugars and also linked to traits such as indeterminate plant habit $(s p+)$, low yield, or small fruit size should be excluded or used with caution. Polymorphisms linked to sugar level and at least some of the traits above are likely because there has already been evidence about correlations between sugar level or SS with traits such as fruit size and plant habit. Emery and Munger(1970) showed that indeterminate tomato plants produced more SS in fruit than isogenic determinate plants. McGillivray and Clemente (1956) showed that smaller fruits had more solids content than larger fruits in 'San Marzano'. Also, Stevens and Rudich (1978) showed that there was an inverse relationship between yield and SS.

\section{Materials and Methods}

FALL 2001. Accession PI 270248 was crossed to Fla.7833-11-1 (7833) and subsequently $\mathrm{F}_{2}$ seeds were obtained. Line 7833 was used as a parent because it had low SS typical of most commercial cultivars, it is determinate, and it has a jointless pedicel that allowed us to determine if plant habit or pedicel type affect fruit sugar levels. Selections were then made to produce $\mathrm{F}_{3}$ and $\mathrm{F}_{4}$ lines with high or low sugars. The parents, $\mathrm{F}_{2}, \mathrm{~F}_{3}$, and $\mathrm{F}_{4}$ were grown in a randomized complete-block design (RCBD) with 3 blocks and 10 plants per plot. However, samples were taken from only 21 plants of PI 270248, as some plants were lost. Seeds were sown in the greenhouse in Black Beauty spent coal (Reed Minerals Div., Highland, Ind.) medium on 27 July, and transplanted into Todd planter flats $\left(3.8 \mathrm{~cm}^{3}\right.$ cell size) (Speedling, Sun City, Fla.) on 6 Aug. They were transplanted to the field on 30 Aug. on 20-cm-high, 81-cm-wide beds of EauGallie fine sand that had been fumigated with $67 \%$ methyl bromide : $33 \%$ chloropicrin at $392 \mathrm{kgha}^{-1}$ and covered with white polyethylene mulch 2 weeks before transplanting. Plants were spaced $46 \mathrm{~cm}$ apart within plots that were $91 \mathrm{~cm}$ apart in rows, with $152 \mathrm{~cm}$ between rows. Recommended fertilizer and insecticide programs were followed (Hochmuth et al., 1988). Plants were grown with stake culture and irrigated by seepage from ditches adjacent to the six experimental beds.

SPRING 2002. The parents and $\mathrm{F}_{2}$ were grown in a RCBD with 4 blocks with 10 plants per plot for the parents and 50 plants per plot for the $\mathrm{F}_{2}$. However, samples were taken from 30 plants of PI 270248, 38 of 7833 and 198 of $\mathrm{F}_{2}$, as some plants were lost. Seeds were sown, as before, in the greenhouse on $11 \mathrm{Jan}$. and transplanted on 25 Jan. They were transplanted to the field on 6 Mar. on fumigated beds covered with black polyethylene mulch 2 weeks before transplanting. Other growing procedures and techniques were the same as in Fall 2001.

Both SEASONS. The habit of each plant (determinate, indeterminate) was noted. Earliness and yield were rated subjectively when the earliest plants had almost $100 \%$ table-ripe fruit. For earliness, plants were rated on a 1-3 scale, where $1=$ very late fruit ripening and $3=$ very early fruit ripening. Yield was determined by taking into account the number and the size of fruits per plant and using a $1-5$ scale, where $1=$ very low yield and $5=$ very high yield. The pedicel type (jointed, jointless) and fruit size were also determined when some fruit were ripe in each plant. For fruit size, a Craftsman caliper was used to measure the average diameter of three to five table-ripe fruits per plant.

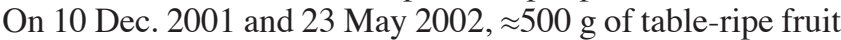
per plant were harvested. Fruits from each plant were ground using a Waring blender and the fruit homogenate was stored in plastic bags at $-20{ }^{\circ} \mathrm{C}$ prior to analysis. Part of that pulp was used to measure sugars and part of it was used for measuring $\mathrm{pH}$, titratable acidity (TA), and SS.

Sugars and acids were extracted using the following procedure: Fruit homogenate ( $40 \mathrm{~g}$ ) was added to $70 \mathrm{~mL}$ of $80 \%$ ethanol, boiled for $15 \mathrm{~min}$ (with a loose-fitting cover), cooled, and vacuumfiltered through Whatman \#4 filter paper. The resulting extract was brought up to $100 \mathrm{~mL}$ with $80 \%$ ethanol; and $12 \mathrm{~mL}$ was then passed through a C-18 Sep Pak (Waters/Millipore, Milford, Mass.) and a $0.45-\mu \mathrm{m}$ Millipore filter. There was $5-8 \mathrm{~mL}$ of filtered extract per plant available for high-performance liquid chromatography (HPLC) analysis (Baldwin et al., 1998).

Sugar measurements were conducted at the USDA Citrus and Subtropical Products Lab in Winter Haven, Fla. The filtered 
extract was injected using a Bio-Rad AS-100 HPLC autosampler (Bio-Rad, Richmond, Calif.), fitted with a $20-\mu \mathrm{L}$ sample loop, into a Perkin Elmer Series 410 HPLC system (Perkin Elmer, Boston, Mass.). Sugars were analyzed using a Waters Sugar Pak column at $90{ }^{\circ} \mathrm{C}$ with a mobile phase of $100 \mu \mathrm{M}$ ethylenediaminetetraacetic acid disodium-calcium salt (CaEDTA) and a flow rate of $0.5 \mathrm{~mL} \cdot \mathrm{min}^{-1}$. A Perkin Elmer LC-25 Refractive Index detector was used to measure sugars (Baldwin et al., 1998). Filtered analytical grade reagents were used for standard preparation to establish HPLC retention times and calibration. Determination of purity of individual peaks was accomplished by absorbance index (all wavelengths monitored simultaneously) on a Perkin Elmer LC-235 Diode Array Detector.

The $\mathrm{pH}$, TA, and SS were measured using the following procedure: Tubes $(50 \mathrm{~mL})$ were filled up with tomato pulp from each plant and were centrifuged at $4000 \mathrm{~g}_{\mathrm{n}}$ for $5 \mathrm{~min}$. The aliquot was filtered through filter paper (Fisher Brand) into $50 \mathrm{~mL}$ beakers and was used to measure $\mathrm{pH}$ with a Corning $\mathrm{pH}$ meter 340 . Two to three drops of filtered aliquot were also used to measure SS content with an Atago-101 digital refractometer. Then, $10 \mathrm{~mL}$ of filtered aliquot were pipetted into $50-\mathrm{mL}$ flasks and five to six drops of phenolphthalein were added. Next $0.1 \mathrm{~N} \mathrm{NaOH}$ was slowly poured into the flasks until phenolphthalein changed from transparent to slightly purple and the amount of $\mathrm{NaOH}$ added was determined. Titratable acidity was measured using the formula: $\mathrm{TA}(\%$ citric acid $)=(\mathrm{mL} 0.1 \mathrm{~N} \mathrm{NaOH}) \times 0.064 \times 100$.

Pearson correlation coefficients (SAS Inst., Cary, N.C.) were determined for total sugars with earliness, yield, fruit size, $\mathrm{pH}$, $\mathrm{TA}$, and SS content. One hundred ninety-eight $\mathrm{F}_{2}$ plants from Spring 2002 were used for analysis. The relationship of total sugars with plant habit and type of pedicel was determined with $t$ test (SAS). The F test was also used to compare the means of all the traits between line PI 270248 and 7833.

RAPD MARKER ANALYSIS. In Fall 2001, DNA was taken from the parents PI 270248 and 7833 , and $\mathrm{F}_{2}, \mathrm{~F}_{3}$, and $\mathrm{F}_{4}$ plants with high or low sugars. Half a rosette leaf was used in each case and DNA was extracted (Doyle and Doyle, 1987). PCR was conducted using a Stratagene Robocycler 96 and the conditions were the following: 1 cycle of $94{ }^{\circ} \mathrm{C}$ for $3 \mathrm{~min}, 40$ cycles of $94{ }^{\circ} \mathrm{C}$ for 1 min, $35^{\circ} \mathrm{C}$ for $1 \mathrm{~min}, 72^{\circ} \mathrm{C}$ for $1.5 \mathrm{~min}$ and 1 cycle of $72^{\circ} \mathrm{C}$ for $7 \mathrm{~min}$. The materials used per reaction (Total volume $=25 \mu \mathrm{L}$ ) were: $50 \mathrm{~mm} \mathrm{KCl}, 10 \mathrm{~mm}$ Tris- $\mathrm{Cl}$ (pH 9.0), 0.1\% Triton-X, 2 mм $\mathrm{MgCl}_{2}, 200 \mu \mathrm{M}$ dNTPs (each), $0.2 \mu \mathrm{M}$ primer, 5-30 ng DNA and $1 \mathrm{U}$ Taq polymerase.

Screening TEChNique. There were 200 Operon and 800 UBC (Univ. of British Columbia) primers tested for polymorphisms between PI 270248 and 7833 . Those that did not yield products or have polymorphic bands were excluded from further analysis. The polymorphic markers were tested with five $\mathrm{F}_{3}$ plants that had very high sugar level vs. three $\mathrm{F}_{3}$ and two $\mathrm{F}_{4}$ plants from lines homozygous for very low sugar levels. Their homozygosity was expected and needed to distinguish high from low sugar plants using dominant RAPD markers. Primers that did not seem to correlate with sugar level were excluded from further analysis. The remaining primers were tested with all $198 \mathrm{~F}_{2}$ plants from Spring 2002.

DataAnalysis. The genetic mapping of the markers was conducted using MAPMANAGER (QTXb15) software (Manly et al., 2001) and confirmed by MAPMAKER 3.0 (Lander et al., 1987). QTL analysis was conducted by MAPMANAGER (QTXb15) software. The purpose of using those programs was to find linkages among the markers, determine which of them were linked to high sugars (in coupling or repulsion), find how much they contribute to the phenotype, and determine which of them were linked to other traits. Linkage of each marker to high sugars was also tested using SAS (SAS Institute, Cary, NC). Markers linked to high sugars were tested whether they fit a 3:1 ratio (dominant markers) in the $\mathrm{F}_{2}$ using chi-square goodness of fit test. The size of the markers was approximated using Alpha Imager $2000 \mathrm{v} 4.03$ software. Finally, the percentage of sugar variation explained by all the markers found was estimated using SAS.

\section{Results and Discussion}

PI 270248 was significantly earlier and had significantly higher sugars, SS, TA, and $\mathrm{pH}$ than 7833 (Table 1). Additionally, PI 270248 had lower yield and fruit size than 7833 . Since PI 270248 and 7833 were significantly different for all traits measured, it was expected that all of them would segregate in the $\mathrm{F}_{2}$ generation. The relationship of sugar level with these traits and some information about relationships between other important traits in the $\mathrm{F}_{2}$ population are in Table 2 . Sugars were strongly correlated $(r>0.9)$ with SS as expected since they constitute a significant part of them (Davies and Hobson, 1981). Thus, SS measurements are a good estimate of sugars.

In this experiment, total sugars (primarily reducing sugars) were positively correlated to $\mathrm{pH}(0.306)$ and $\mathrm{TA}(0.395)$ and both correlations were highly significant $(P<0.001)$. The correlation of $\mathrm{pH}$ and TA was negative $(-0.445)$. The positive correlation between sugar and TA confirms data from previous research where cherry tomato 'Cervil' was used (Saliba-Colombani et al., 2001). Reports on correlations between sugar and $\mathrm{pH}$ have varied widely and they have been positive, negative, or insignificant (Bernacchi et al., 1998; Saliba-Colombani et al., 2001; Tanksley et al., 1996). A positive correlation of tomato fruit sugar with both TA and $\mathrm{pH}$ has not yet been reported. However, Anderson (1957) suggested that there were lines with both high $\mathrm{pH}$ and $\mathrm{TA}$, and cases where $\mathrm{pH}$ and TA were not always inversely correlated. Stevens (1986) suggested that both of them should be measured in tomato to determine the organoleptic quality of the fruit. The positive correlation of sugar with $\mathrm{pH}$ in this experiment may be an obstacle in an effort to transfer sugars from PI 270248 to cultivars with suitable acidity for processing. The positive correlation between sugars and $\mathrm{pH}$ and between sugars and TA means that plants with high sugars generally have more free organic acids (citric and malic acid) and less hydrogen ion concentration $(\mathrm{pH})$ than plants with low sugars. Thus, it is not known whether the transfer of high sugars from PI 270248 will also transfer a more sour flavor. In the future, taste panels may be help answer this question.

Indeterminate plants had higher mean sugar concentration than determinate plants (Table 3 ). This is in agreement with what Emery and Munger (1970) have shown. They suggested that their results may be explained by the fact that indeterminate plants have more leaves per fruit than do determinate plants. In Florida, determinate plants are the predominant type grown. Therefore, breeders may face an additional problem trying to transfer high sugars from the indeterminate PI 270248 to determinate largefruited tomatoes.

Fruit size was negatively correlated to sugars $(-0.468, P<$ $0.001)$ and this confirmed what other researchers have shown (Goldman et al., 1995; McGillivray and Clemente, 1956; SalibaColombani et al., 2001). However, it has not been delineated if this is mostly due to linked genes or genes with pleiotropic effects. There is a tendency to accept the second possibility as the 
Table 1. Comparison of tomato inbreds PI 270248 and Fla.7833 for sugars, soluble solids, titratable acidity, pH, earliness, yield, and fruit size in Spring 2002 at Bradenton, Fla.

\begin{tabular}{lccccccc}
\hline Genotype & $\begin{array}{c}\text { Sugar } \\
(\mathrm{g} / 100 \mathrm{~g} \text { fresh wt })\end{array}$ & $\begin{array}{c}\mathrm{SS}^{\mathrm{z}} \\
(\%)\end{array}$ & $\begin{array}{c}\mathrm{TA}^{\mathrm{z}} \\
(\% \text { citric acid })\end{array}$ & $\mathrm{pH}$ & Earliness $^{\mathrm{y}}$ & Yieldy $^{\mathrm{y}}$ & $\begin{array}{c}\text { Fruit size } \\
(\mathrm{cm})^{\mathrm{w}}\end{array}$ \\
\hline PI 270248 & $5.00^{* x}$ & $8.03^{*}$ & $0.60^{*}$ & $4.36^{*}$ & $3^{*}$ & $2.0^{*}$ & 2.0 \\
Fla.7833 & 2.17 & 3.80 & 0.31 & 4.22 & 1 & 4.5 & $10.0^{*}$
\end{tabular}

${ }^{\mathrm{z}} \mathrm{SS}=$ soluble solids content, $\mathrm{TA}=$ titratable acidity.

ystimated on a 1-5 scale where higher numbers indicate more earliness or yield, respectively.

x*Indicates a significantly greater value in column by $t$ test at $P \leq 0.05$.

Table 2. Correlation coefficients ( $r$ ) of total sugars with soluble solids (SS), glucose, fructose, fructose/glucose, titratable acidity (TA), $\mathrm{pH}$, yield, earliness, and fruit size from an $\mathrm{F}_{2}$ population between tomato inbreds PI 270248 and Fla. 7833 in Spring 2002 at Bradenton, Fla.

\begin{tabular}{lc}
\hline Trait & Sugar \\
\hline SS & $0.923^{* * *}$ \\
Glucose (Glu) & $0.995^{* * *}$ \\
Fructose (Fru) & $0.995^{* * *}$ \\
Fru/Glu & $-0.387^{* * * *}$ \\
pH & $0.306^{* * *}$ \\
TA & $0.395^{* * *}$ \\
Yield & -0.043 \\
Earliness & -0.124 \\
Fruit size & $-0.468^{* * *}$ \\
\hline
\end{tabular}

****Indicates significance at $P<0.001$. Other significant correlations at $P<0.001$ were $\mathrm{pH}-\mathrm{SS}$ $=0.263, \mathrm{TA}-\mathrm{SS}=0.577, \mathrm{TA}-\mathrm{pH}=-0.445$, and earliness-fruit size $=-0.28$.

Table 3. Effect of plant habit and pedicel type on fruit sugar levels for an $\mathrm{F}_{2}$ population between tomato inbreds PI 270248 and Fla. 7833 at Bradenton, Fla., in Spring 2002.

\begin{tabular}{lcc}
\hline & $\begin{array}{c}\text { Plants } \\
\text { (no.) }\end{array}$ & $\begin{array}{c}\text { Sugar } \\
(\mathrm{g} / 100 \mathrm{~g} \\
\text { fresh wt) }\end{array}$ \\
Trait & & \\
\hline Plant habit & & $3.68^{*}$ \\
$\quad$ Indeterminate & 144 & 2.98 \\
$\begin{array}{l}\text { Determinate } \\
\text { Pedicel type }\end{array}$ & 54 & 3.51 \\
$\quad \begin{array}{l}\text { Jointed } \\
\text { Jointless }\end{array}$ & 160 & 3.42 \\
\hline "Indicates a significantly greater value for plant \\
habit by $t$ test at $P \leq 0.05$.
\end{tabular}

negative correlation has been observed in many cases. Stevens (1986) suggested that large fruits tend to have more water in the cells, which dilutes sugars and lowers their concentration. The negative correlation was quite strong in this experiment and it will probably be difficult to transfer high sugars from PI 270248 to large-fruited inbreds.

The correlation between sugars and yield was insignificant in contrast to the negative correlations previously reported between yield and sugars or SS (Bernacchi et al., 1998; Saliba-Colombani et al., 2001; Stevens and Rudich, 1978). The negative correlation, shown in previous research, may be explained by the fact that plants with high yield may also have a high ratio of fruit/leaf tissue and thus, they cannot provide fruit with as much carbohydrate as plants with a lower ratio. However, in our research the ratio of fruit/leaf tissue did not seem to be a problem. This is encouraging to breeders as it shows that it may be possible to uncouple high sugars from low yield to some extent. However, once high sugars are moved into more advanced high-yielding backgrounds, a negative association of high sugars and yield might yet be encountered.

It might be expected that plants that ripen their fruits earlier have less time to provide them with carbohydrates, and thus sugars, than plants that ripen later. Although earliness did not show a significant correlation with sugars, there was a significant negative correlation between earliness and fruit size (Table 2) indicating plants with smaller fruit tended to be earlier than those with larger fruit. Since there was a significant correlation between small fruit and high sugars (Table 2), the lack of a correlation between high sugars and earliness might indicate that there is a tendency for lower sugars in earlier maturing tomato plants. Finally, there was no relationship between pedicel type and sugar level $(P=$ 0.258) (Table 3).

It is not known if plant habit and fruit size will be insurmountable obstacles to transferring high sugars to determinate, large-fruited tomatoes. The transfer would appear to be difficult but it may not be necessary to transfer the entire high level [5 $\mathrm{g} / 100 \mathrm{~g}$ fresh weight (FW)] of sugars from PI 270248 for flavor improvement. An increase up to $3.5 \mathrm{~g} / 100 \mathrm{~g} \mathrm{FW}$ would likely noticeably increase sweetness over most existing cultivars and may be easier to achieve.

Of 800 UBC primers (Univ. of British Columbia) and 200 OPERON primers tested with PI 270248 and 7833,148 of them did not produce any visible band. The rest gave a total of 5964 bands (seven bands per primer) while 235 primers gave 303 polymorphic bands between the parents. Six primers produced seven bands linked to high sugars in the $\mathrm{F}_{2}$ population, five in coupling and two in repulsion (Table 4). It was observed that two bands produced by UBC 269 primer segregated as allelic in the $\mathrm{F}_{2}$ generation as they fit a 1:2:1 ratio (Table 4). Thus, the two bands were considered as one co-dominant marker. The rest of the markers yielded bands that segregated in the $\mathrm{F}_{2}$ population of spring 2002 fit the 3:1 ratio as expected (Table 4). Figure 1 depicts the bands linked to high sugars while Table 5 shows the sugar means of the plants with and without the markers. Three markers (OPAE 4, UBC 731, UBC 489) were in one linkage group, two (UBC 744 , UBC 290) were in another linkage group, while one (UBC 269) was unlinked. The linkages between UBC 744 and UBC 290, and between UBC 731 and UBC 489 were significant at $P$ $<0.001$, while the linkage between OPAE 4 and UBC 731 was significant only at $P<0.01$. The former indicates linkage while the latter is just suggestive. Hence, OPAE 4 may not be linked to UBC 731 and UBC 489. Identification of markers in at least three regions suggests polygenic control of sugars. The polygenic control of sugars has also been reported with other high sugar sources (Fulton et al., 2002; Saliba-Colombani et al., 2001). However, an estimate of the number of these genes would be very speculative at this point. It is possible that there were more genes affecting sugars, but markers linked to them were not found. In a recent study, Saliba-Colombani et al. (2001) used a cross between the cherry tomato 'Cervil' and the large-fruited tomato 'Levovil'. They constructed a genetic map using mainly RFLPs with some RAPDs and about four QTLs for sugar were found. One of the markers significantly linked to high sugars in that study was OPERON 
Table 4. Band size of RAPD markers linked to high sugars in an $\mathrm{F}_{2}$ population between tomato inbreds PI 270248 and Fla. 7833 grown at Bradenton, Fla., in Spring 2002 and chi-square tests for goodness of fit for control by single genes.

\begin{tabular}{|c|c|c|c|c|c|c|c|}
\hline $\begin{array}{l}\text { Primer } \\
\text { (Marker) }\end{array}$ & $\begin{array}{l}\text { Band size } \\
\text { (kilobases) }\end{array}$ & $\begin{array}{c}\text { PI } 270248 \\
\text { pattern }\end{array}$ & $\begin{array}{c}\text { PI } 270248 X \\
\text { Fla.7833 } \\
\text { pattern }\end{array}$ & $\begin{array}{c}\text { Fla. } 7833 \\
\text { pattern }\end{array}$ & $\begin{array}{l}\text { Expected } \\
\text { ratio }\end{array}$ & $\chi^{2}$ & $P$ \\
\hline $\begin{array}{l}\text { OPAE4 } \\
\text { (OP4) }\end{array}$ & 0.90 & 144 & --- & 54 & $3: 1$ & 0.545 & 0.460 \\
\hline UBC269 & 1.76 & & & & & & \\
\hline (269) & 1.65 & 52 & 98 & 48 & $1: 2: 1^{z}$ & 0.182 & 0.913 \\
\hline $\begin{array}{l}\text { UBC731 } \\
(731)\end{array}$ & 1.07 & 50 & --- & 148 & $1: 3$ & 0.007 & 0.933 \\
\hline $\begin{array}{l}\text { UBC744 } \\
(744)\end{array}$ & 1.20 & 153 & --- & 45 & $3: 1$ & 0.545 & 0.460 \\
\hline $\begin{array}{l}\text { UBC489 } \\
(489)\end{array}$ & 0.59 & 152 & --- & 46 & $3: 1$ & 0.330 & 0.566 \\
\hline $\begin{array}{l}\text { UBC290 } \\
\text { (290) }\end{array}$ & 0.83 & 159 & --- & 39 & $3: 1$ & 2.969 & 0.085 \\
\hline
\end{tabular}

${ }^{\mathrm{z}}$ Ratio is for the three patterns in the row, respectively.
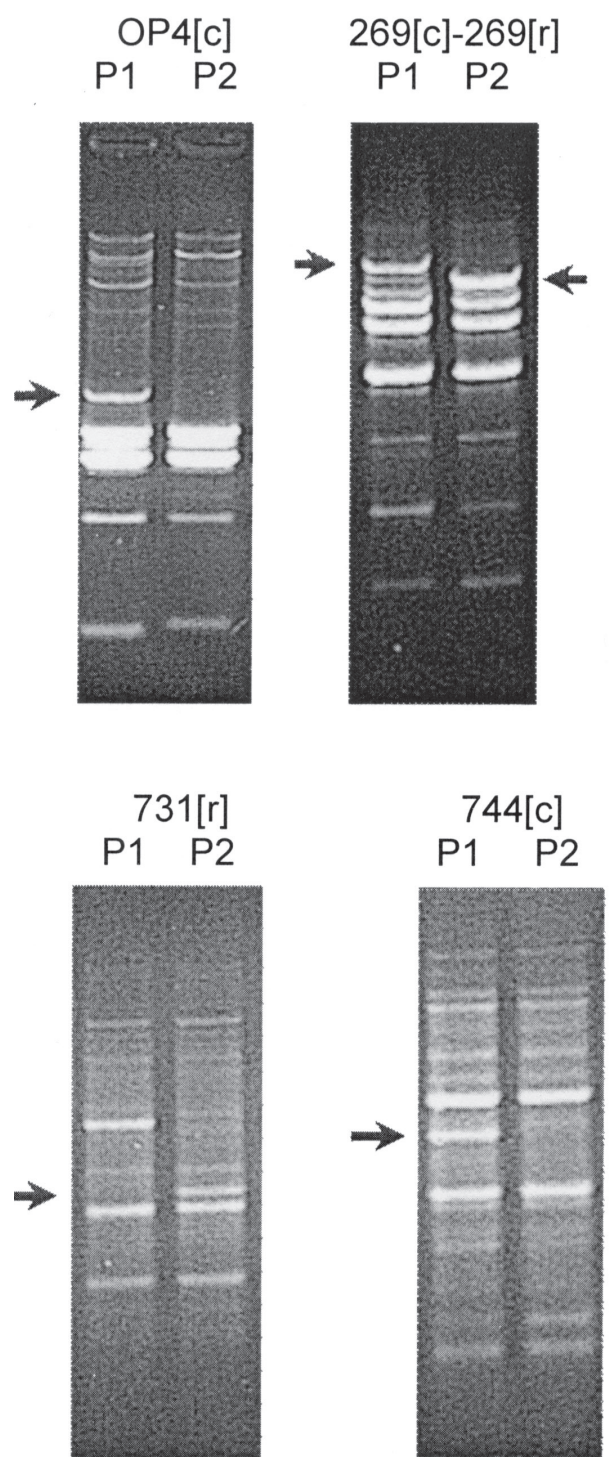



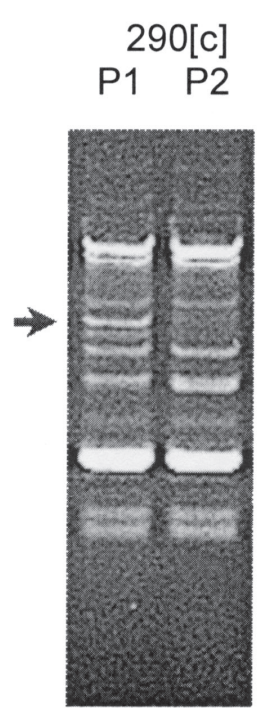

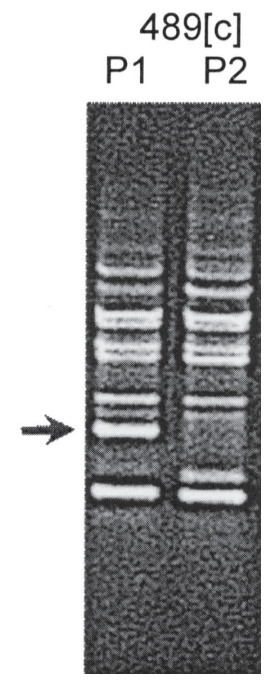

primer OPAE4. This primer was also linked to high sugars in the present experiment, where it explained $18 \%$ of the phenotypic variation in the $\mathrm{F}_{2}$ generation. Another marker that explained a fair amount of variation (16\%) was UBC 744. The rest of the markers, although significantly linked to high sugars, explained no more than $4 \%$ to $5 \%$ of the phenotypic variation. Unfortunately, the chromosomal location of the markers was not identified. Saliba-Colombani et al. (2001) showed that OPAE 4 marker was found on chromosome 2. In this experiment, OPAE 4 was located 45.3 centimorgans (cM) away from UBC 731, which was, in turn, linked to UBC 489 (34.3 cM). Since $45.3 \mathrm{cM}$ is very close to independent assortment and the linkage between OPAE 4 and UBC 731 was only significant at $P<0.01$, it cannot be definitely concluded that UBC 731 and UBC 489 were located on chromosome 2.

The markers identified could also be used in fine mapping programs in tomato. Apart from sugars, most of them were linked to fruit size, yield, SS, pH, or TA (Table 6). So, they can contribute along with other markers to find a more precise location of QTLs affecting all these traits. This could clarify if some of the traits that are correlated to each other are closely linked genes or genes with pleiotropic effects.

One of the goals of this research was to find markers useful for MAS to transfer high sugars to large-fruited tomatoes. It would be desirable that these markers be closely linked to genes controlling high sugars and not linked to genes controlling other undesirable traits. Unfortunately, two markers (OPAE 4, UBC 744) explaining 18\% and 16\%, respectively, of the sugar variation in the $\mathrm{F}_{2}$ population were also linked to small fruit size and explained $21 \%$ and $22 \%$ of the fruit size variation. This means that plants with the markers had generally high sugars, but also small fruit size. Marker UBC 290

Table 5. Mean sugar concentration for plants from an $F_{2}$ population between tomato inbreds PI 270248 and Fla. 7833 with or without various RAPD markers at Bradenton, Fla., in Spring 2002.

\begin{tabular}{lccc}
\hline Marker $^{z}$ & Group & $\begin{array}{c}\text { Sugars } \\
(\mathrm{g} / 100 \mathrm{~g} \text { fresh wt })\end{array}$ & $\begin{array}{c}\text { Plants } \\
(\text { no. })\end{array}$ \\
\hline $744(\mathrm{c})$ & $(+)$ & 3.60 & 153 \\
& $(-)$ & 3.15 & 45 \\
$731(\mathrm{r})$ & $(-)$ & 3.70 & 50 \\
& $(+)$ & 3.40 & 148 \\
269 & $(\mathrm{~A})$ & 3.69 & 52 \\
& $(\mathrm{H})$ & 3.49 & 48 \\
& $(\mathrm{~B})$ & 3.32 & 98 \\
OP4(c) & $(+)$ & 3.63 & 144 \\
& $(-)$ & 3.13 & 54 \\
$290(\mathrm{c})$ & $(+)$ & 3.56 & 159 \\
& $(-)$ & 3.32 & 39 \\
$489(\mathrm{c})$ & $(+)$ & 3.56 & 152 \\
& $(-)$ & 3.33 & 46 \\
\hline
\end{tabular}

zFor marker abbreviations see Table 4, in addition: (c) = coupling, $(\mathrm{r})=$ Fig. 1. Six RAPD markers; OP4, 269, 290, 731, 744, and 489 that were linked to high repulsion, $(+)=$ plants with the band, $(-)=$ plants without the band, A sugars where $\mathrm{c}=$ coupling, $\mathrm{r}=$ repulsion, $\mathrm{P} 1=\mathrm{PI} 270248$, and $\mathrm{P} 2=7833$. Arrows $=$ homozygotes for the $1.76 \mathrm{~kb}(\mathrm{kilobase})$ band, $\mathrm{H}=$ heterozygous, $\mathrm{B}=$ point to the polymorphic bands. homozygotes for the $1.65 \mathrm{~kb}$ band. 
Table 6. Phenotypic variation of an $\mathrm{F}_{2}$ population between tomato inbreds PI 270248 and Fla. 7833 grown at Bradenton, Fla., in Spring 2002 for sugar, $\mathrm{pH}$, titratable acidity (TA), yield, soluble solids (SS), plant habit, and fruit size that was detected by linked markers.

\begin{tabular}{lccccccc}
\hline & \multicolumn{7}{c}{ Phenotypic variation (\%) } \\
\cline { 2 - 7 } Marker $^{2}$ & Sugar & SS & TA & pH & Fruit size & Yield & $\begin{array}{c}\text { Indeterminate } \\
\text { plant habit }\end{array}$ \\
\hline 269 & $3^{*}$ & NL & NL & $9^{* * *}$ & NL & NL & $9^{* * *}$ \\
OP4 & $18^{* * *}$ & $30^{* * *}$ & $15^{* * *}$ & NL & $21^{* * *}(-)$ & NL & NL \\
744 & $16^{* * *}$ & $22^{* * *}$ & $14^{* * *}$ & $4^{* *}$ & $22^{* * *}(-)$ & NL & NL \\
290 & $4^{*}$ & $5^{*}$ & $8^{* *}$ & NL & $18^{* * *}(-)$ & $7^{* *}(-)$ & NL \\
731 & $6^{* * *}(-)$ & $12^{* * *}(-)$ & $16^{* * *}(-)$ & NL & $8^{* * *}$ & NL & NL \\
489 & $3^{*}$ & 6 & $20^{* * *}$ & $7^{* * *}(-)$ & $4^{*}(-)$ & NL & NL
\end{tabular}

zFor abbreviations see Table 4.

${ }^{*},{ }^{*},{ }^{* * *}$ Significance at $P<0.05,<0.01$, and $<0.001$, respectively; $(-)=$ negative effect on the phenotype; $\mathrm{NL}=$ not linked.

Table 7. Mean sugar concentration for plants from an $\mathrm{F}_{2}$ population between tomato inbreds PI 270248 and Fla. 7833 grown at Bradenton, Fla., in Spring 2002 with various combinations of markers and their frequency in the population. ${ }^{2}$

\begin{tabular}{lccc}
\hline Combination & $\begin{array}{c}\text { Sugar } \\
(\mathrm{g} / 100 \mathrm{~g} \text { fresh wt })\end{array}$ & $\begin{array}{c}\mathrm{F}_{2} \text { plants } \\
(\text { no. })\end{array}$ & $\begin{array}{c}\text { Plants } \\
(\%)\end{array}$ \\
\hline $\begin{array}{l}\text { 1) } 744(\mathrm{c}) \\
731(\mathrm{r})\end{array}$ & 3.850 & 42 & 21.0 \\
2) $744(\mathrm{c})$ & & & \\
$731(\mathrm{r})$ & 3.900 & 37 & \\
OP4(c) & & & \\
3) 269 & 3.970 & 29 & 14.5 \\
OP4(c) & & & \\
$489(\mathrm{c})$ & & 21 & \\
4) $744(\mathrm{c})$ & 3.995 & & \\
269 & & & \\
OP4(c) & & & \\
$489(\mathrm{c})$ & &
\end{tabular}

${ }^{\mathrm{z} F o r}$ marker abbreviations see Table 4 , in addition: $(\mathrm{c})=$ coupling, $(\mathrm{r})=$ repulsion, $\%=$ percentage of plants selected out of the $\mathrm{F}_{2}$ population.

explained just $4 \%$ of sugar variation, but it was linked to small fruit size (18\% of variation) and low yields (7\%). Markers UBC 731 and UBC 489 were also linked to small fruit size, while the co-dominant marker 269, which was not linked to small fruit size, was linked to indeterminate habit (9\%). The question remains whether all these markers can be used in a MAS program without transferring low yield, small fruit size or indeterminate habit to the recurrent parents. It is recommended that UBC 290 should be avoided. It was either closely linked to a weak gene or loosely linked to a strong gene for high sugars because it only explained $4 \%$ of the phenotypic variation. Additionally, it seemed to have a closer linkage to small fruit size (18\%) and low yield $(7 \%)$. Finally, all the markers were linked to $\mathrm{pH}$ or TA or both (Table 6). Selecting for high sugars using these markers would likely increase TA that is highly correlated to free acids (Paulson and Stevens, 1974). A change in $\mathrm{pH}$ is not clear but it also seems to be increased by most markers. A balance between sweetness and sourness has been shown to be important for a good overall flavor (Jones and Scott, 1984; Malundo et al., 1995). The simultaneous transfer of the sourness along with sweetness to a large-fruited tomato may not disturb the balance and promote, in this way, a more acceptable flavor. Sourness depends on both $\mathrm{pH}$ and TA (Harvey, 1920). Thus, it is not clear if a simultaneous transfer of sweetness and sourness might be achieved using the markers found in this research.
All the markers together explained $35 \%$ of sugar variation in the $\mathrm{F}_{2}$ (data not shown). Almost $86 \%$ of the sugar variation was explained by genetic variation in Spring 2002 (Georgelis, 2002). Thus, 51\% of the genetic sugar variation was not explained by the markers. There are several possible explanations for this. First, there were more genes affecting sugars, but no markers linked to them were found. Second, some of the markers were not very closely linked to genes affecting sugars. Finally, five of six markers linked to high sugars were not co-dominant, thus heterozygous plants with non-dominant sugar control are grouped with one of the homozygous classes increasing experimental variability.

None of the markers by themselves explained much sugar variation. Thus, combinations of markers may be necessary for modified backcrossing in breeding programs. All the possible combinations of markers were tested, and the ones with a high sugar average and a reasonable population size were selected (Table 7). The population sizes used could give breeders the opportunity to select against small fruit size, low yield and indeterminate plant habit. High sugars could be confirmed by measuring SS, as the correlation between the two was very high $(r=0.92)$. In almost half of the best combinations of markers, UBC 731 is found (linked to sugars in repulsion). This marker may be more useful in breeding than anticipated by the $5 \%$ of the sugar variation it explained. For UBC 731, the heterozygotes that may have relatively high sugars were incorporated into the homozygotes with low sugars, raising the sugar mean. Thus, the sugar difference between the classes with and without the marker may be greatly reduced and thus the explained phenotypic variation would also be reduced. However, by selecting against the UBC 731 marker, some heterozygotes with high sugars would be eliminated leaving plants homozygous for high sugars. The sugar mean of plants remaining after selecting against UBC 731 was $3.7 \mathrm{~g} / 100 \mathrm{~g}$ FW compared to plants selected for OPAE 4 and UBC 744 (3.63 and 3.6, respectively).

Another disadvantage of many RAPDs was their poor reproducibility. Often, the results were extremely sensitive to changes in factors affecting PCR. It would be much easier to use the markers found in this experiment in a breeding program if they were converted to sequence characterized amplified region (SCAR) markers, which would be fairly reproducible. SCARs could also verify that 269 is a co-dominant marker. Our markers also need to be tested with different low sugar parents. In this research, they were tested with 7833 , but they would only be useful to breeding efforts if they worked with different low sugar lines.

To summarize, it seems that most of the markers linked to high sugars were not linked to low yield or indeterminate habit and this means that sugars can be uncoupled to some extent from these traits. However, the question about whether high sugars could be uncoupled from small fruit size remains unanswered since five out of six markers of this research with linkage to high sugars were also linked to small fruit size. Our results corroborate previous research that has shown a negative correlation between sugars and fruit size (McGillivray and Clemente, 1956). This correlation has also been illustrated by co-localization of QTLs of these traits on chromosomes 2, 3, and 11 (Goldman et al., 1995; Paterson et al., 1991; Saliba-Colombani et al., 2001). 
Since these co-localizations have been found in many cases, it may be assumed that part the negative correlation between sugars and fruit size is due to pleiotropic effects of some genes (physiological relationship), since other research supports pleiotropy (McGillivray and Clemente, 1956). However, there may be genes like the one linked to the co-dominant marker UBC 269, found in this research, that affect sugars without an effect on fruit size. These genes may be suitable for transferring a significant part of sweetness from small-fruited to large-fruited tomatoes and markers like UBC 269 may be useful. However, markers like OPAE 4, UBC 744, UBC 489, and UBC 731 should not be excluded from MAS programs, because they may help to transfer enough sweetness to enhance the overall flavor without significantly reducing the fruit size.

\section{Literature Cited}

Anderson, R.E. 1957. Factors affecting the acidic constituents of the tomato. PhD Diss., Univ. of Illinois, Champaign-Urbana, Ill.

Baldwin, E.A., J.W. Scott, M.A. Einstein, T.M.M. Malundo, B.T. Carr, R.L. Shewfelt, and K.S. Tandon. 1998. Relationship between sensory and instrumental analysis for tomato flavor. J. Amer. Soc. Hort. Sci. 125:906-915.

Baldwin, E.A., J.W. Scott, C.K. Shewmaker, and W. Schuch. 2000. Flavor trivia and tomato aroma: Biochemistry and possible mechanisms for control of important aroma components. HortScience 35:1013-1022.

Bernacchi, D., T. Beck-Bunn, Y. Eshed, J. Lopez, V. Petiard, J. Uhlig, D. Zamir, and S. Tanksley. 1998. Advanced backcross QTL analysis in tomato. I. Identification of QTLs for traits of agronomic importance from Lycopersicon hirsutum. Theor. Appl. Genet. 97:381-397.

Biester, A.M. 1925. Carbohydrate studies. I. Relative sweetness of pure sugars. Amer. J. Physiol. 73:387-400.

Bruhn, C.M., N. Feldman, C. Garlitz, J. Harwood, E. Ivans, M. Marshall, A. Riley, D. Thurber, and E. Williamson. 1991. Consumer perceptions of quality: Apricots, cantaloupes, peaches, pears, strawberries, and tomatoes. J. Food Qual. 14:187-195.

Causse, M., V. Saliba-Colombani, I. Lesschaeve, and M. Buret. 2001. Genetic analysis of organoleptic quality in fresh market tomato. 2. Mapping QTLs for sensory attributes. Theor. Appl. Genet. 102:273-283.

Davies, J.N. and G.E. Hobson. 1981. The constituents of tomato fruit-The influence of environment, nutrition, and genotype. CRC Critical Rev. Food Sci. Nutr. 15:205-280.

Davies, J.N. and R.J. Kempton. 1975. Changes in the individual sugars of tomato fruit during ripening. J. Sci. Food Agr. 26:1103-1110.

Doyle, J.J. and J.L. Doyle. 1987. A rapid DNA isolation procedure from small quantities of fresh leaf tissues. Phytochem. Bul. 19:11-15.

Emery, G.C. and H.M. Munger. 1970. Effects of inherited differences in growth habit on fruit size and soluble solids in tomato. J. Amer. Soc. Hort. Sci. 95:410-412.

Foolad, M.R., R.A. Jones, and R.L. Rodriguez. 1993. RAPD markers for constructing intraspecific tomato genetic maps. Plant Cell Rpt. 12:293-297.

Fulton, T.M., P. Bucheli, E. Voirol, J. Lopez, V. Petiard, and S.D. Tanksley. 2002. Quantitative trait loci (QTL) affecting sugars, organic acids and other biochemical properties possibly contributing to flavor, identified in four advanced backcross populations of tomato. Euphytica 127:163-177.

Georgelis, N. 2002. High fruit sugar characterization, inheritance, and linkage of molecular markers in tomato. MS thesis. Univ. of Florida, Gainesville.

Goldman, I.L., I. Paran, and D. Zamir, 1995. Quantitative trait locus analysis of a recombinant inbred line population derived from a $L y$ copersicon esculentum $\times$ Lycopersicon cheesmanii cross. Theor. Appl. Genet. 90:925-932.

Harvey, R.B. 1920. The relation between the total acidity, the concentration of the hydrogen ion and the taste of the acid solutions. J. Amer. Chem. Soc. 42:712-714.

Hochmuth, G.J., D.N. Maynard, and M. Sherman. 1988. Tomato production guide for Florida. Fla. Coop. Ext. Circ. 98C.

Jones, R.A. and C.O. Qualset. 1984. Breeding crops for environmental stress tolerance, p. 305-340. In: G.B. Collins and J.F. Petolino (eds.). Application of genetic engineering to crop improvement. Nijhoff/Junk Publishers, The Hague, The Netherlands.

Jones, R.A. and S.J. Scott. 1984. Genetic potential to improve tomato flavor in commercial $F_{1}$ hybrids. J. Amer. Soc. Hort. Sci. 109:318-321.

Kader, A.A., M.A. Stevens, M. Albright-Holton, L.L. Morris, and M. Agazi. 1977. Effect of fruit ripeness when picked on flavor and composition in fresh market tomatoes. J. Amer. Soc. Hort. Sci. 102:724-731.

Kavanagh, E.E. and W.B. McGlasson. 1983. Determination of sensory quality in fresh market tomatoes. CSIRO Food Res. Quart. 43:81-89.

Kazeniac, S.J. and R.M. Hall. 1970. Flavor chemistry of tomato volatiles. J. Food. Sci. 35:519-530.

Krumbein,A. and H. Auerswald. 1998. Characterization of aroma volatiles in tomatoes by sensory analysis. Nahrung 42:395-399.

Lander, E.S., P. Green, J. Abrahamson, A. Barlow, M.J. Daly, S.E. Lincoln, and L. Newburg. 1987. MAPMAKER: An interactive computer package for constructing primary genetic linkage maps of experimental and natural populations. Genomics 1:174-81.

Levin, I., N. Gilboa, E. Yeselson, S. Shen, and A.A. Schaffer. 2000. Fgr, a major locus that modulates the fructose to glucose ratio in mature tomato fruits. Theor. Appl. Genet. 100:256-262.

Malundo, T.M.M., R.L. Shewfelt, and J.W. Scott. 1995. Flavor quality of fresh market tomato (Lycopersicon esculentum Mill.) as affected by sugar and acid levels. Postharvest Biol. Technol. 6:103-110.

Manly, K.F., R.H. Cudmore, Jr., and J.M. Meer. 2001. Map Manager QTX, cross-platform software for genetic mapping. Mamm. Genome 12:930-932.

McGillivray, J.H. and L.J. Clemente. 1956. Effect of tomato size on solids content. Proc. Amer. Soc. Hort. Sci. 68:466-469.

McGlasson, W.B., J.B. Sumeghy, L.L. Morris, R.L. McBride, D.J. Best, and E.C. Tigchelaar. 1983. Yield and evaluation of $F_{1}$ tomato hybrids incorporating the non-ripening nor gene. Austr. J. Expt. Agr. 23:106-112.

Paterson, A.H., S. Damon, J.D. Hewitt, D. Zamir, H.D. Rabinowitch, S.E. Lincoln, E.S. Lander, and S.D. Tanksley. 1991. Mendelian factors underlying quantitative traits in tomato: Comparison across species, generations, and environments. Genetics 127:181-197.

Paulson, K.N. and M.A. Stevens. 1974. Relationships among titratable acidity, $\mathrm{pH}$ and buffer composition of tomato fruits. J. Food Sci. 39:254-357.

Petro-Turza, M. 1987. Flavor of tomato and tomato products. Food Rev. Intl. 2:309-351

Saliba-Colombani, V., M. Causse, D. Langlois, J. Philouze, and M. Buret. 2001. Genetic analysis of organoleptic quality in fresh market tomato. 1. Mapping QTLs physical and chemical traits. Theor. Appl. Genet. 102:259-272.

Scott, J.W. 2002. A breeder's perspective on the use of molecular techniques for improving fruit quality. HortScience 37:464-467.

Scott, J.W., G.C. Somodi, and J.B. Jones. 1989. Resistance to bacterial spot fruit infection in tomato. HortScience 24:825-827.

Stevens, M.A. 1972. Relationships between components contributing to quality variation among tomato lines. J. Amer. Soc. Hort. Sci. 97:70-73.

Stevens, M.A. 1986. Inheritance of tomato fruit quality components. Plant Breeding Rev. 4:273-311.

Stevens, M.A., A.A. Kader, M. Albright-Holton, and M. Algazi. 1977a. Genotypic variation for flavor and composition in fresh market tomatoes. J. Amer. Soc. Hort. Sci. 102:680-689.

Stevens, M.A., A.A. Kader, and M. Albright-Holton. 1977b. Intercultivar variation in composition of locular and pericarp portions of fresh market tomatoes. J. Amer. Soc. Hort. Sci. 102:689-692.

Stevens, M.A. and J. Rudich. 1978. Genetic potential for overcoming physiological limitations on adaptability, yield, and quality in the tomato. HortScience 13:673-678.

Tandon, K.S., E.A. Baldwin, and R.L. Shewfelt. 2000. Aroma perception of individual volatile compounds in fresh tomatoes (Lycopersicon esculentum Mill.) as affected by the medium of evaluation. Postharvest Biol. Technol. 20:261-268.

Tanksley, S.D., S. Grandillo, T.M. Fulton, D. Zamir, Y. Eshed, V. Petiard, J. Lopez, and T. Beck-Bunn. 1996. Advanced backcross QTLanalysis in a cross between an elite processing line of tomato and its wild relative L. pimpinellifolium. Theor. Appl. Genet. 1996:213-224. 